CASE REPORT

\title{
Unoperated tetralogy of Fallot: case report of a natural survivor who died in his 73rd year; is it ever too late to operate?
}

\author{
$X$ Yang, L J Freeman, C Ross
}

Postgrad Med J 2005;81:133-134. doi: 10.1136/pgmi.2004.020172

The case history is described of a man in his 73rd year who was one of the oldest surviving patients with uncorrected tetralogy of Fallot (ToF) before succumbing with renal failure. Factors contributing to his longevity included small pulmonary arteries and presumed slow development of subpulmonary obstruction together with moderate concentric left ventricular hypertrophy-features previously seen in long term survivors. Less than $3 \%$ of all patients with uncorrected ToF survive beyond their 40 s but late operative repair is still a valuable option. Practicalities of renal dialysis in the presence of an intracardiac shunt are considered.

$\mathrm{T}$ tralogy of Fallot (ToF), first described in 1888, comprises an interventricular septal defect, right ventricular outflow tract obstruction, an overriding aorta, and right ventricular hypertrophy $(\mathrm{RVH}) .{ }^{1}$ It is the most common form of cyanotic congenital heart disease ( $10 \%$ of all cases). ${ }^{2}$ This case describes a man in his 73rd year who was one of the oldest surviving patients with an uncorrected ToF before succumbing with renal failure. We review the factors contributing to his longevity and consider whether surgery in his 66th year would have been appropriate.

\section{CASE PRESENTATION}

The patient, described as having a weak heart in childhood, never attended school or played sports. Diagnosis of ToF was not made until the age of 31 (1961) but he defaulted from further investigations. In 1996 (aged 66 years) he was reassessed while being investigated for proteinuria ( urea $=5.7 \mathrm{mmol} / \mathrm{l} ; \mathrm{Cr}=98 \mu \mathrm{mol} / \mathrm{l}$ ). He was asymptomatic. He was mildly cyanosed and clubbed with pectus carinatum. Blood pressure was $140 / 80 \mathrm{~mm} \mathrm{Hg}$. He had an ejection systolic murmur in the pulmonary area. Echocardiography disclosed a subaortic VSD with a left to right shunt of $1.94 \mathrm{~m} / \mathrm{s}$, minimal aortic override (diameter $3.76 \mathrm{~cm}$ ), small volume, hypertrophied well contracting $\mathrm{LV}, \mathrm{RVH}$, dilated RA, bicuspid pulmonary valve with a small pulmonary artery $(1.4 \mathrm{~cm})$, subpulmonary stenosis with an RVOT gradient of $112 \mathrm{~mm} \mathrm{Hg}$, and moderate PR. Electocardiography confirmed sinus rhythym, voltage criteria for RVH; RBBB with a QRS duration of $100 \mathrm{~ms}$. Chest radiography showed a right aortic arch. Holter monitoring disclosed one asymptomatic 4 beat burst of SVT. Exercise testing terminated at four minutes because of fatigue $\left(\mathrm{O}_{2}\right.$ saturation fell from $91 \%$ to $\left.80 \%\right)$. The decision was made for medical management rather than surgical correction in view of his advanced age, asymptomatic status, and personal wishes. At the age of 69 the patient complained of regular fast palpitations and associated dyspnoea. The echocardiogram showed severely hypertrophied and impaired RV function, huge RA $(6.8 \times 8.2 \mathrm{~cm})$,

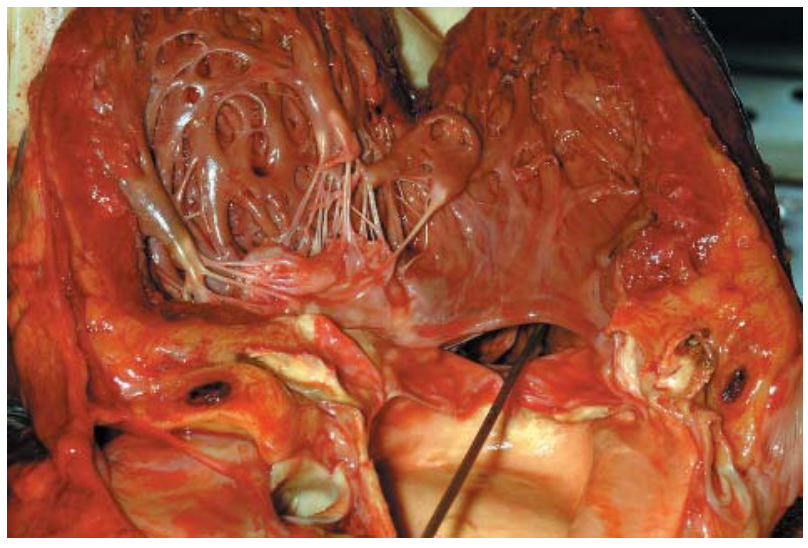

Figure 1 Postmortem findings of $2 \mathrm{~cm}$ ventricular septal defect (VSD), overriding aorta, and left ventricular hypertrophy (LVH).

normal LV dimensions with moderate concentric hypertrophy as before, and a dilated LA $(5.82 \mathrm{~cm})$. Creatinine was $118 \mu \mathrm{mol} / \mathrm{l}$. He was treated with frusemide, spironolactone, amiodarone, and aspirin. His renal function deteriorated in his 72 nd year ( urea $=18.5 \mathrm{mmol} / \mathrm{l} ; \mathrm{Cr}=174 \mu \mathrm{mol} / \mathrm{l}$ ), and he needed thyroxine for amiodarone induced hypothyroidism. He was never polycythaemic. In his 73rd year he had new onset $\mathrm{AF}$, at which time his urea was $43.9 \mathrm{mmol} / \mathrm{l}$ and his creatinine was $436 \mu \mathrm{mol} / \mathrm{l}$. He was cardioverted and treated with haemodialysis - the presumed diagnosis being acute on chronic renal failure (acute tubular necrosis) associated with hypotension secondary to AF. Renal ultrasound excluded obstructive uropathy. Four weeks later, AF recurred and despite cardioversion he remained hypotensive and unwell and died three days later. At postmortem examination the pericardial sac was obliterated with a dense fibrinous pericarditis. The heart was enlarged $(565 \mathrm{~g}$ ) with massive enlargement of the right atrium and right ventricle. There was pronounced subpulmonary stenosis with an effective outflow tract of $10 \mathrm{~mm}$; the pulmonary valve was bicuspid and the annulus was only $13 \mathrm{~mm}$. The LA was moderately dilated and the LV was concentrically hypertrophied; there was no infarction. The VSD was $2 \mathrm{~cm}$ in diameter and abutted the aortic valve ring (fig 1). There was $90 \%$ stenosis of the RCA and recent heamorrhage into a proximal plaque, an $80 \%$ LAD stenosis, and a blocked circumflex. There were no systemic pulmonary anastamoses; lungs were oedematous. Macroscopically, the kidneys showed cortical atrophy

Abbreviations: ToF, tetralogy of Fallot; $\mathrm{RVH}$, right ventricular hypertrophy; LA, left atrium; RA, right atrium; LV, left ventricle; RVOT, right ventricle outflow tract; VSD, ventricular septal defect; LAD, left anterior descending 
but postmortem autolysis prevented microscopic interpretation.

\section{DISCUSSION}

Without operation, few patients with ToF reach adulthood with an average life expectancy of 12 years. Ten per cent may survive to their 30 s but only $3 \%$ reach their 40 s or older. ${ }^{3}$ There are three main reasons for the longevity in natural survivors with unoperated ToF. Firstly, a hypoplastic pulmonary artery with slow development of subpulmonary obstruction. ${ }^{4}$ The pulmonary annulus was $13 \mathrm{~mm}$ in this patient, comparable to that reported in the other published cases-(age 45, PVD $10 \mathrm{~mm}){ }^{4}$ (age 77, PVD $\left.9 \mathrm{~mm}\right){ }^{5}$ A second common feature is that of LVH as seen in this patient ( $16 \mathrm{~mm}$ ); presumably this acts by delaying of shunting from the right to left ventricle. ${ }^{67} \mathrm{LVH}$ may be a late development in the natural history of Fallot and any beneficial effect may not be seen until adult life. In this case hypoplasia of the pulmonary artery (seen in up to $50 \%$ of all Fallot's) may have been sufficient early on to reduce pulmonary blood flow; then the subpulmonary stenosis needs to have also developed slowly over decades while his left ventricular hypertrophied concomitantly. Such a fine haemodynamic balance is clearly rare. The third finding in other cases has been extracardiac shunts including patent ductus arteriosus - reported in the oldest survivor who died aged $77^{5}$ - or systemic to pulmonary artery shunting via internal mammaries. ${ }^{9}$ There are few studies on the outcome and benefit of late surgical repair. The Mayo series followed up 30 patients who had total correction of ToF between the ages of 40 to 60 years. ${ }^{10}$ The operative mortality was 3\% with long term survival rate at 5 years and 10 years postoperatively of $92 \%$ and $74 \%$ respectively. In this case, surgical repair would have been possible at the age of 66 years with low operative mortality and is likely to have prevented his subsequent systemic venous congestion. Nevertheless his personal wishes were not for operationbut given similar circumstances, operation would be recommended. Preoperative catheterisation also would have disclosed his coronary artery disease, which was unrecognised and untreated and probably had a role in his terminal decline. It is always important to consider detailed reinvestigation of any new elderly patient given a label of inoperable congenital heart disease as new approaches may be available to palliate the condition. He remained in sinus rhythm for a long time given his atrial dimensions; this undoubtedly improved his longevity and is probably a testament to amiodarone. His rapid decline was heralded by the change to atrial fibrillation resulting in pre-renal failure-which was not a consequence of his longstanding congenital heart disease. Dialysis in patients with intracardiac shunts requires antibiotic prophylaxis at the time of line insertion, use of a blood filter downstream from the bubble trap on the venous limb of the dialysis circuit to avoid paradoxical embolism together with avoidance of rapid fluid removal, which may precipitate hypotension and exacerbate shunt reversal.
Learning points

- Few patients with tetralogy of Fallot survive into adulthood without operation

- Unoperated survivors have three common features: hypoplastic pulmonary artery with moderately slow development of subpulmonary obstruction, left ventricular hypertrophy, or systemic-pulmonary artery collaterals for pulmonary blood flow.

- Late operative intervention is associated with low mortality - it may never be too late to operate.

- Full re-investigation of older patients labelled as "inoperable" congenital heart disease may sometimes permit late palliation.

- Renal dialysis in the presence of an intracardiac shunt requires bubble filters to prevent paradoxical embolism

\section{Authors' affiliations}

$X$ Yang, Department of Internal Medicine, Duke University Medical Centre, Durham, North Carolina, USA

L J Freeman, GUCH Unit, Department of Cardiology, Norfolk and Norwich University NHS Hospital, Norwich, UK

C Ross, Department of Renal Medicine, Norfolk and Norwich University NHS Hospital

Correspondence to: Dr L J Freeman, GUCH Unit, Department of Cardiology, Norfolk and Norwich University NHS Hospital, Colney Lane, Norwich NR4 7UZ, UK; leisa.freeman@nnuh.nhs.uk

Submitted 6 February 2004

Accepted 4 April 2004

\section{REFERENCES}

1 Fallot ELA. Contribution à l'anatomie pathologique de la maladie bleue (cyanose cardiaque). Marseille Médical 1888;25:77-93, 138-58, 207-23, 341-54, 370-86, 403-20

2 Freeman $L$, Woods S, Hardiman T, et al. Adult congenital heart disease (or GUCH) clinic in a district general hospital: the Norfolk and Norwich experience. Br J Cardiol 2002;9:92-8.

3 Bertranou EG, Blackstone EH, Hazelrig JB, et al. Life expectancy without surgery in tetralogy of Fallot. Am J Cardiol 1978;42:458-66.

4 Meindok $\mathrm{H}$. Longevity in the tetralogy of Fallot. Thorax 1964;19:12-15.

5 Thomas SHL, Bass P, Pambakian H, et al. Cyanotic tetralogy of Fallot in a 77 years old man. Postgrad Med J 1987;63:361-2.

6 Bowie EA. Longevity in tetralogy and triology of Fallot. Discussion of cases in patients surviving 40 years and presentation of two further cases. Am Heart $J$ $1961 ; 62: 125-32$.

7 Chin J, Bashour T, Kabbani S. Tetralogy of Fallot in the elderly. Clin Cardiol 1984;7:453-6.

8 Nottestad SY, Slife DM, Rubal BJ, et al. Tetralogy of Fallot in a 71 year old patient with new onset hypoxemia. Cathet Cardiovasc Diagn 1993;28:335-8.

9 Liberthson RR, Miller SW, Drew F, et al. Congenital extracardiac shunts with tetralogy of Fallot. Cardiovasc Intervent Radiol 1981;4:131-5.

10 Hu DCK, Seward JB, Puga FJ, et al. Total correction of tetralogy of Fallot at age 40 years and older: long-term follow-up. J Am Coll Cardiol 1985;5:40-4. 